(2)

\section{OPEN ACCESS}

${ }^{1}$ School of Medicine, Indira Gandhi Medical College, Himachal Pradesh, India ${ }^{2}$ School of Medicine, Oregon Health and Science University, Portland, Oregon, USA ${ }^{3}$ Department of Medicine, Oregon Health and Science University, Portland, Oregon, USA

\section{Correspondence to} Dr André Martin Mansoor; mansooan@ohsu.edu

Accepted 3 March 2020

\title{
Jugular venous pulse in constrictive pericarditis
}

\author{
Ishita Sharma, ${ }^{1}$ Joseph Girard Nugent $\odot_{1}{ }^{2}$ Peter D Sullivan, ${ }^{3}$ André Martin Mansoor ${ }^{3}$
}

\section{DESCRIPTION}

A 61-year-old woman with a history of orthotopic heart transplantation for familial hypertrophic cardiomyopathy 20 years previously was admitted to the hospital with subacute, progressive, exertional dyspnoea. Quantitative assessment of the jugular venous pulse demonstrated a jugular venous pressure (JVP) of $16 \mathrm{~cm} \mathrm{H}_{2} \mathrm{O}$, while qualitative assessment revealed a paradoxical rise in JVP with inspiration, along with sharp and deep $\mathrm{x}$ and y descents (figure 1 and video 1 ).

Transthoracic echocardiography showed normal left and right ventricular function. MRI of the heart showed pericardial thickening and enhancement, diastolic bounce of the interventricular septum, and respirophasic septal shift with ventricular interdependence. Right heart catheterisation demonstrated sharp and deep $\mathrm{x}$ and $\mathrm{y}$ descents of the right atrial pressure tracing (figure 2). The constellation of clinical, imaging and invasive haemodynamic findings was

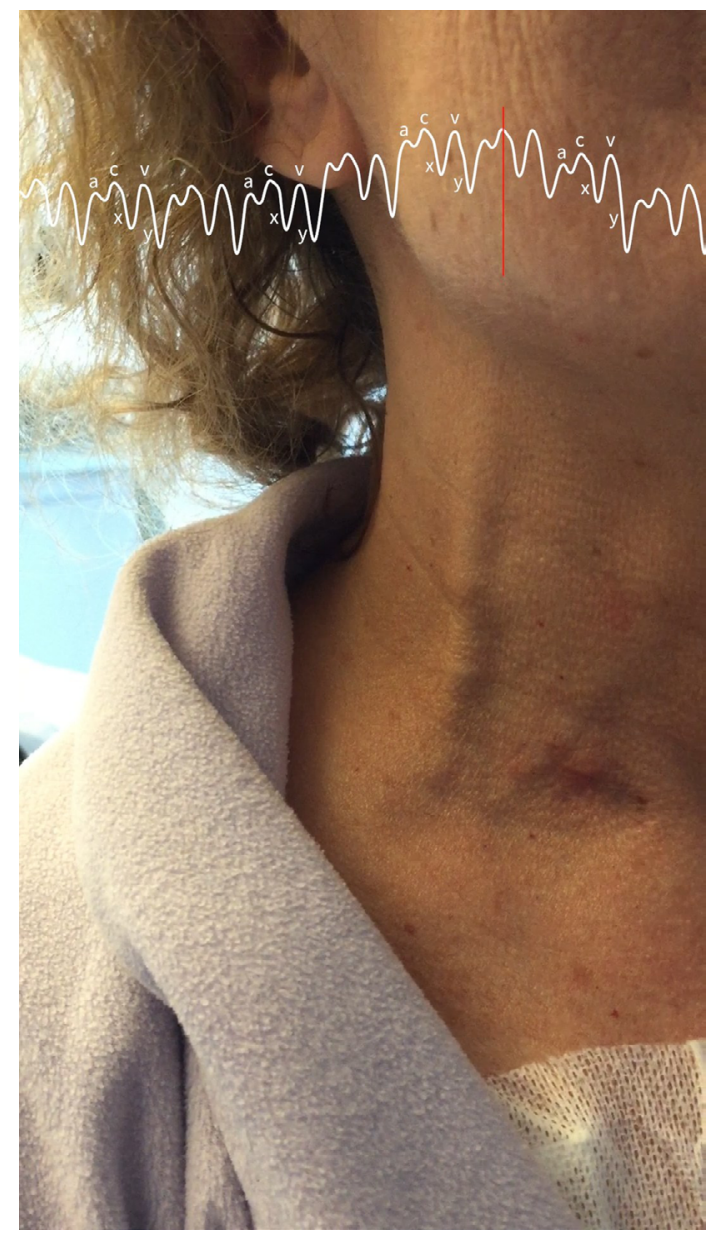

Figure 1 Engorged neck veins in a patient with constrictive pericarditis.

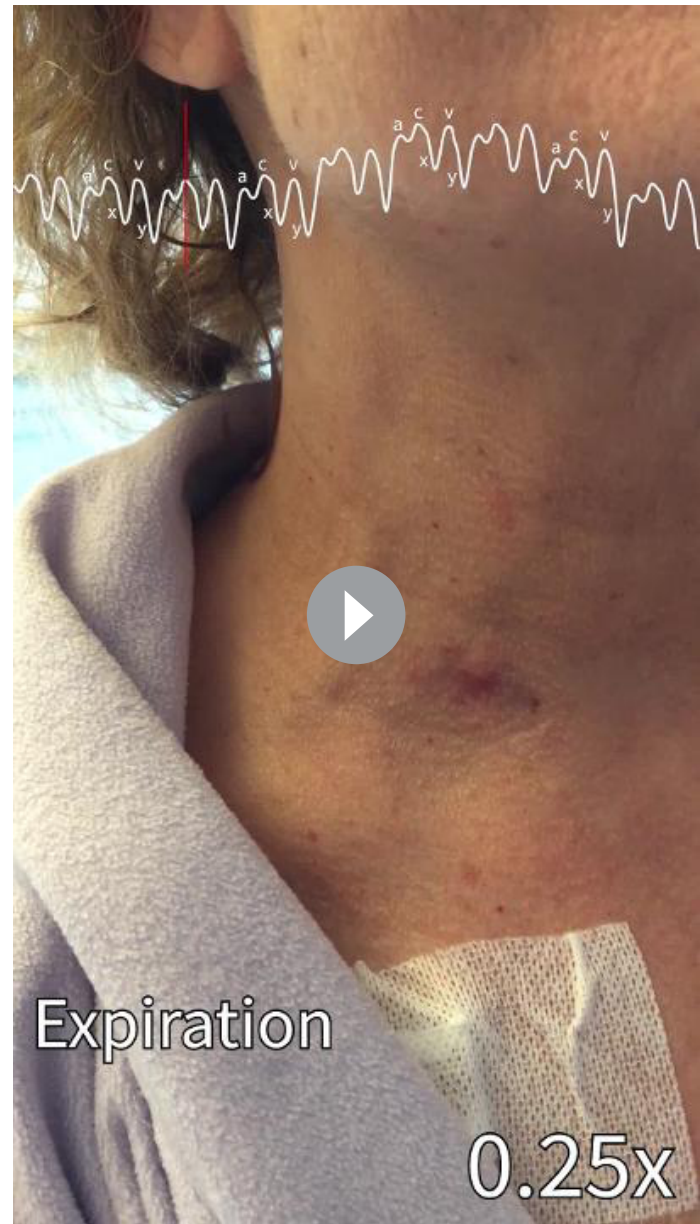

Video 1 Paradoxical rise in JVP with inspiration, known as Kussmaul's sign, along with sharp and deep $x$ and y descents, known as the ' $W$ ' sign, in a patient with constrictive pericarditis. The right atrial pressure tracing from the patient is superimposed on the video and synchronised with the jugular venous waveform. Note that c waves are not clinically observable at the bedside.

consistent with constrictive pericarditis, a rare sequela of heart transplantation. ${ }^{1}$ Sternotomy confirmed the presence of a dense pericardium encasing the allograft. Following radical pericardiectomy and repeat orthotopic heart transplantation, the patient's symptoms resolved, and she has returned to her usual active lifestyle.

Under normal conditions, decreased intrathoracic pressure during inspiration augments venous return to the right side of the heart, which is easily accommodated by a compliant right ventricle, leading to a decrease in JVP. The paradoxical rise in JVP with inspiration, known as Kussmaul's sign, occurs in the setting of impaired right ventricular filling from any cause, including constrictive pericarditis. $^{2}$ 


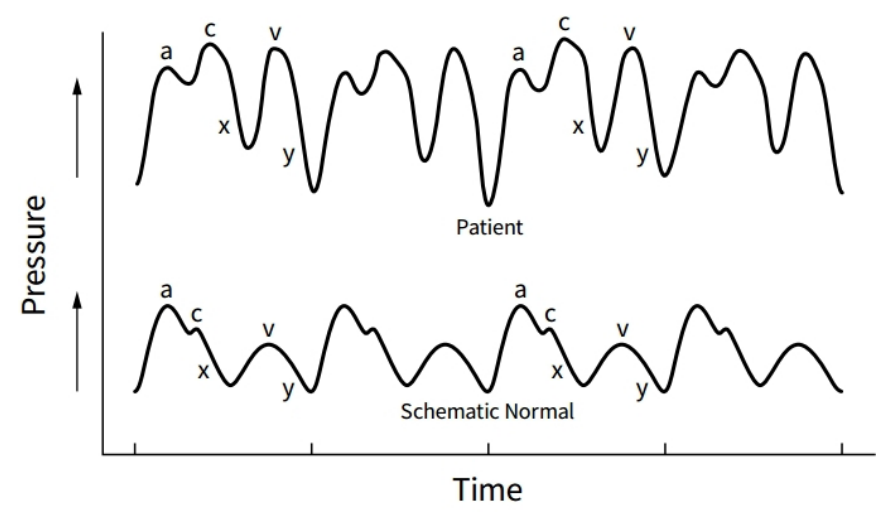

Figure 2 Right atrial pressure tracing of the patient (top strip) demonstrating sharp and deep $x$ and y descents, known as the ' $W$ ' sign, compared with a schematic representation of normal findings (bottom strip).

\section{Learning points}

- The paradoxical rise in jugular venous pressure (JVP) with inspiration, known as Kussmaul's sign, and a sharp and deep y descent of the jugular venous waveform, known as Friedreich's sign, are nonspecific physical findings of constrictive pericarditis.

- The combination of sharp and steep $x$ and $y$ descents of the jugular venous waveform, known as the ' $W$ ' sign, is a physical finding of constrictive pericarditis and can be helpful in differentiating constrictive pericarditis from restrictive cardiomyopathy.

- Chronic constrictive pericarditis is a rare complication of orthotopic heart transplantation. Pericardiectomy is the mainstay of treatment and typically leads to rapid symptomatic improvement. In early cases, or when surgery is contraindicated, diuretic medications may be used to improve symptoms.

- In heart transplant recipients who develop right-sided heart failure, constrictive pericarditis should be included in the differential diagnosis, along with more common causes, such as rejection of the allograft, restrictive cardiomyopathy and cardiac allograft vasculopathy.
The components of the jugular venous waveform that are clinically observable at the bedside include the a wave, $x$ descent, $v$ wave and $y$ descent. Under normal conditions, the $x$ descent is more prominent than the $y$ descent. In constrictive pericarditis, the unyielding pericardium causes elevated atrial pressure and limits ventricular filling to the early diastolic period. The resultant brisk and enhanced early diastolic filling produces a sharp and deep y descent, known as Friedreich's sign. ${ }^{3}$ In the absence of atrial fibrillation, the prominent $y$ descent often occurs in combination with a prominent $\mathrm{x}$ descent, creating two steep troughs known as the 'W' sign. This finding may be helpful in distinguishing constrictive pericarditis from restrictive cardiomyopathy, in which the $\mathrm{x}$ descent is typically diminished. ${ }^{45}$

Twitter Joseph Girard Nugent @jgnugent

Contributors All authors were involved in writing the manuscript. AMM recorded the clinical video. JGN annotated the video.

Funding The authors have not declared a specific grant for this research from any funding agency in the public, commercial or not-for-profit sectors.

Competing interests None declared.

Patient consent for publication Obtained.

Provenance and peer review Not commissioned; externally peer reviewed.

Open access This is an open access article distributed in accordance with the Creative Commons Attribution Non Commercial (CC BY-NC 4.0) license, which permits others to distribute, remix, adapt, build upon this work non-commercially, and license their derivative works on different terms, provided the original work is properly cited and the use is non-commercial. See: http://creativecommons.org/ licenses/by-nc/4.0/.

\section{ORCID iD}

Joseph Girard Nugent http://orcid.org/0000-0002-6863-4523

\section{REFERENCES}

1 Bansal R, Perez L, Razzouk A, et al. Pericardial constriction after cardiac transplantation. J Heart Lung Transplant 2010;29:371-7.

2 Mansoor AM, Karlapudi SP, Sign Kussmaul's. Images in clinical medicine. Kussmaul's sign. N Engl J Med 2015;372:e3.

3 Pittenger B, Sullivan PD, Mansoor AM. Friedreich's sign. BMJ Case Rep 2018;2018. doi:10.1136/bcr-2018-226820. [Epub ahead of print: 16 Oct 2018]

4 Geske JB, Anavekar NS, Nishimura RA, et al. Differentiation of constriction and restriction: complex cardiovascular hemodynamics. J Am Coll Cardiol 2016:68:2329-47.

5 Wood P. Chronic constrictive pericarditis. Am J Cardiol 1961;7:48-61.

Copyright 2020 BMJ Publishing Group. All rights reserved. For permission to reuse any of this content visit https://www.bmj.com/company/products-services/rights-and-licensing/permissions/

BMJ Case Report Fellows may re-use this article for personal use and teaching without any further permission.

Become a Fellow of BMJ Case Reports today and you can:

- Submit as many cases as you like

- Enjoy fast sympathetic peer review and rapid publication of accepted articles

- Access all the published articles

- Re-use any of the published material for personal use and teaching without further permission

Customer Service

If you have any further queries about your subscription, please contact our customer services team on +44 (0) 2071111105 or via email at support@bmj.com.

Visit casereports.bmj.com for more articles like this and to become a Fellow 